\title{
Providing Services for Elderly in Rural India - Is Anganwadi Centres a feasible option?
}

\author{
Sonali Sarkar
}

\section{Sonali Sarkar}

Associate Professor

Department of Preventive and Social

Medicine

JIPMER, Pondicherry - 605006, INDIA

\section{Correspondence}

Dr. Sonali Sarkar, Department of Preventive and Social Medicine, JIPMER, Pondicherry, INDIA

Email: sarkarsonaligh@gmail.com

\section{History}

- Submission Date: 28-06-2016;

- Accepted Date: 29-06-2016.

DOI : 10.5530/ijmedph.2016.2.1

Article Available online

http://www.ijmedph.org/v6/i2

\section{Copyright}

(C) 2016 Phcog.Net. This is an open-access article distributed under the terms of the Creative Commons Attribution 4.0 International license.

\section{Most vulnerable among the elderly}

The proportion of elderly defined as those above 60 years of age in India is increasing; from $7.4 \%$ of the overall population in 2011 it is expected to be over $10 \%$ in 2021 , a projected increase from 76 million to approximately 140 million. ${ }^{1}$ Old age is the period of life when the physical ability wanes and morbidities are on a rise, therefore considered a vulnerable population. But the elderly have not received enough attention till a policy "The National Policy on Older Persons (NPOP)" was announced by the government in 1999 and a programme, the National Programme for Health Care of the Elderly (NPHCE) was launched in 2010-11. The National Policy on Senior Citizens 2011 rightly recognizes the most vulnerable among the elderly that is the rural poor and the women. ${ }^{2}$ In India, three-fourths of elderly are in the rural areas, the percentage share being 7.6 in rural compared to 7.2 in urban as per the NSSO 2007-08. ${ }^{1}$ Poverty too is more acute a problem for rural elderly than the urban. Most of India's poor are in rural areas ${ }^{3}$ and so also the elderly. The oldage-dependency ratio is $14 \%$ (2001) in rural areas whereas it is between 8 to $10 \%$ in urban areas. ${ }^{1}$ Most poor families in rural areas are barely able to meet their daily subsistence and therefore have no savings for their old age. ${ }^{2}$ Poverty disproportionately affects the rural elderly women. Women outlive their male partners, life expectancy at birth being 64.2 years for females and 62.6 for males. At age 60, women have an average of 18.9 years more of life compared to 16.7 for men. Living longer with lesser employment, the female old-age dependency ratio is higher (13.8\%) than males $(12.5 \%)$, which is of serious concern given the fact that the proportion of female elderly of the total population is increasingly steeply compared to the male elderly. ${ }^{1}$

\section{Problems of the rural elderly}

The trend in migration from rural to urban areas has been mainly among the younger population leaving the elderly in the villages alone and unattended. Physical ailments like musculoskeletal problems, poor vision and sleep disorders are accompanied with high prevalence of neuropsychiatric disorders. In a study conducted in a village in Pondicherry, a Union Territory in South India, the rural elderly reported that the old-age pension provided under the Indira Gandhi National Old Age Pension Scheme (IGNOAPS) was not sufficient to meet their essential requirements like food and medical expenses. ${ }^{4}$ Depression among the Indian elderly has been quoted to be higher and especially among the rural elderly. ${ }^{5,6}$ The disabilities are also higher in rural elderly; 64/1000 elderly in rural areas suffer from disabilities compared to 55/1000 in urban areas. At the age when they need to be cared for about 2-3\% of the elderly males and $7-8 \%$ of the elderly females live alone. ${ }^{1}$ Some have to live with other relations or non-relations; where there is no assurance that their needs will be met rather they face neglect and abuse. The overall picture of the elderly in rural India is that of lonely poverty-stricken old women more than men, with higher morbidity, disability and depression, many of who are either living alone or with other relatives or non-relatives and are not being adequately cared for. Compared to the urban there is also a lack of resources and services in the rural areas.

\section{Community based care for the rural elderly}

Elderly people can contribute to their families and society in many ways if they can maintain good health and mobility. For this to happen their nutritional requirements and health problems including the neuropsychiatric need to be addressed adequately. The institutional mechanism to provide health care services to the elderly as envisaged in the NPHCE is limited to the sub-centre level. A subcentre, which covers a population of 5000 and nearly 5 villages is not easily accessible to all the elderly in the villages under them. Therefore a system has to be developed that can provide care for the elderly closer to their homes and covers not only health services but also addresses the social and psychological issues of the elderly.

\section{Why AWC can provide services to the rural elderly?}

In India, there is a wide network of Anganwadicentres(AWC) under the Integrated Child Development Services Scheme (ICDS) managed by the Ministry of Women and Child Develop- 
ment, Govt of India, 13.46 lakh being operational in 2014-15. ${ }^{7}$ They serve a population of approximately 1000 , that is one for every village, most commonly located in the poorest section of the community. The AWCmanned by one Anganwadi worker (AWW) and one helper were started with the objectives of improving nutritional and health status of children aged 0-6 years and have been provided the basic minimum infrastructure. Their activities include providing supplementary nutrition to children below 6 years and pregnant and lactating women, health check-up, referral services and nutrition and health education. Many states have added many non-ICDS activities in the functions of the AWC. In Pondicherry, the AWW are responsible for disbursing the old-age pension. So every elderly in the villages is aware and accessing the services of the AWCs. It is also observed that the utilization of AWC services by children in well-performing states like Pondicherry is declining as most children above 3 years are attending schools and are receiving services like mid-day meals, immunization and health check-ups from the schools. In such settings, the AWC, many of which have their own buildings and are under utilized can be used to provide care for the elderly. A project under the ICMR-adhoc scheme was conducted by the author to provide daycare services to the elderly in a village in Pondicherry utilizing the space available in one of the centrally located AWC. The centre was found to be accessible to almost all the elderly in the village except the most moribund ones. ${ }^{8}$ Therefore the reasons why the AWC can be considered for providing care to elderly in rural areas is 1 ) easy accessibility even for elderly women,

2) familiarity of the elderly with the centres,

3) availability of space,

4) AWW is from the community and understands their issues well and that

5) some of the services for children can be extended to the elderly.

\section{What services can be provided?}

First of the main strategies stated in the NPHCE, the preventive and promotive health care services such as regular physical exercise, balanced diet, vegetarianism, stress management, avoidance of smoking or tobacco products and prevention of fall can be provided in the AWC by expanding the current activities to include supplementary nutrition for the elderly, health check-ups with support from the Primary Health Centres, referral and health education.The AWC can be developed in the lines of the daycare centres in the west, which offer rehabilitation programs, social interaction with peers and participation in campaigns, meals and physical activities providing a chance to socialize in a community-based group. ${ }^{9}$ The Adult Day Services (ADS) in United States of America (USA) support the health, nutritional, social, and daily living needs of adults with functional limitations in a group setting during daytime hours. ${ }^{10}$ The activities can be tailored to the rural Indian setting to include physiotherapy, games to improve their physical and cognitive functions, recreational activities like watching television, reading out stories by the literate to the illiterate ones and counseling on quitting tobacco and alcohol among elderly males.

For planning to provide such services through the AWC, the ministries of Health and Family Welfare and Women and Child Development should work together to conduct feasibility studies in different settings as the availability of infrastructure and functioning of AWC varies from state to state. Training has to be provided to the existing AWW and helpers. But, additional resources like staff and equipment may also be required for such an initiative. The best way will be for each state and district to assess their Strength Weakness Opportunities and Threats (SWOT analysis) in using AWC for the elderly. Plans and models of care can be developed at the state level depending on the feasibility. In the long run such models of care may be a cost-effective option given the increasing number of elderly.We have delayed enough but cannot ignore further the state of affairs of the elderly in rural areas of India. What we do for the elderly today is for our tomorrow.

\section{REFERENCES}

1. Central Statistics Office Ministry of Statistics \&Programme Implementation Government of India. Situation Analysis Of The Elderly in India. New Delhi: 2011 June. 6, 27p.

2. National Policy on Senior Citizens 2011 [Internet]. [cited 2016 June 29]. Available from: socialjustice.nic.in/writereaddata/UploadFile/dnpsc.pdf.

3. International Institute for Population Sciences (IIPS) and Macro International. 2007. National Family Health Survey (NFHS-3), 2005-06: India: Volume I: chapter 2; 43-44. Mumbai: IIPS.

4. Sarkar S, Shivanand K, Premarajan K C, Roy G. Old Age Pension for Elderly in Rural Puducherry: Utilisation for Health and Quality of Life. Journal of The Indian Academy of Geriatrics. 2015;11:10-5.

5. Barua A. Trend of the prevalence of geriatric depression: a modern silent epidemic. International Journal of Collaborative Research on Internal Medicine \& Public Health. 2013;5(1):37-47.

6. Maity M, Mukhhopadhyay B. Depression in late life: a comparative study among elderly inhabiting in different environmental settings. BOOK OF PROCEEDINGS Volume 1. International Congress on Social \& Cultural Studies. September 4-8, 2012 Port Harcourt, Nigeria. p.225-35.

7. Ministry of Women \& Child Development, India - ICDS [Internet]. [cited 2016 June 29]. Available from http://icds-wcd.nic.in/icds/icds.aspx

8. ICMR.nic.in [Internet]. Extramural research projects- Project Information System. [cited 2016 June 29].Available from http://icmr.nic.in/icmrsql/ex_pl.asp

9. Vinay P, Prerna P, Asha K, et al. General \& Mental Health and Life Attitude: a Comparative Study of the elderly living with Family and at Day Care Centre. Open Access Scientific Reports. [cited 2016 June 29]. Available from http:// omicsonline.org/scientific-reports/srep214.php.

10. National Adult Day Services Association (NADSA). (2011). Historical highlights. [cited 2016 June 29]. Available from http://www.nadsa.org/?page_id=125

Cite this article : Sarkar S. Providing Services for Elderly in Rural India - Is Anganwadi Centres a feasible option?. Int. J. Med. Public Health, 2016; 6(2):57-58. 